T.1 $\left\{\begin{array}{l}\text { Revista internacional } \\ \text { de Historia } \\ \text { de la Comunicación }\end{array}\right.$

\title{
LITERATURA DE PROPAGANDA RELIGIOSA EXTRANJERA SOBRE LA GUERRA CIVIL ESPAÑOLA
}

DOI: http://dx.doi.org/10.12795/RiHC.2014.102.03

Antonio César Moreno Cantano

Universidad de Alcalá

antoniomorenocantano@hotmail.com

Recibido: 23-7-13

Aceptado: 13-12-2013

Resumen: El presente estudio profundiza en el conocimiento de las culturas de guerra mediante el análisis de los principales folletos propagandísticos extranjeros que centraron sus miras en el aspecto religioso de la contienda bélica española. El interés prioritario estará en los textos belgas, franceses y alemanes. Detrás de estas iniciativas se encontraba un proceso de adhesión interna y de reafirmación ideológica frente a las ideologías extranjeras. Analizaremos los aspectos comunes, tanto temáticos como lingüísticos, con especial énfasis también en el material fotográfico empleado para llamar la atención del lector.

Palabras claves: Literatura, Propaganda, Relatos de terror, Catolicismo, Guerra Civil.

Abstract: This study explores the knowledge of the cultures of war by analyzing major foreign propaganda leaflets focused their sights on the religious aspect of the Spanish military conflict. The primary interest is in the texts Belgian, French and German. 
Behind these initiatives was a process of internal bonding and ideological reaffirmation against foreign ideologies. Analyze commonalities, both thematic and linguistic, with emphasis also on the photographic material used to call the reader's attention.

Keywords: Literature, Propaganda, Tales of Terror, Catholicism, Civil War

\section{Introducción}

El artículo del profesor Eduardo González Calleja sobre la naturaleza y características de los conflictos armados nacionales subraya en uno de sus párrafos el interés que siempre ha despertado este tipo de conflictos entre los observadores extranjeros, que se ven "forzados" a contemplar el proceso bélico desde un lado u otro de la trinchera dialéctica entre legalidad y subversión ${ }^{1}$. Si aplicamos este condicionante a nuestra pasada guerra civil, veremos que se constituyeron desde primer hora dos coaliciones de escritores y propagandistas foráneos que se sirvieron de la pluma para iniciar una auténtica guerra ideológica por defender o condenar las argumentaciones y acciones de los dos bandos enfrentados en la Península Ibérica.

Un tema capital dentro de las culturas de guerra en el siglo XX ha sido el religioso. En el presente estudio queremos aportar nuevos datos y enfoques sobre las más destacadas publicaciones que, desde la esfera internacional, centraron su atención en la imposible convivencia entre quienes hacían del catolicismo su seña de identidad y quienes la consideraban una herramienta de opresión sobre los principios de libertad. Nuestro eje de análisis se basará en la interrelación de tres elementos: Propaganda, Literatura y Religión.

Un ensayo de naturaleza investigadora similar fue el establecido recientemente por el profesor Hugo García, que analizó los relatos de terror rojo que las autoridades franquistas elaboraron entre 1936 y 1939, interpretando los mismos como un «género literario propio» y no como un simple "apéndice de la propaganda sublevada» ${ }^{2}$. Partiendo de consideraciones metodológicas parecidas, extendemos nuestro objeto de estudio a los escritos religiosos que tanto el bando franquista como el republicano emplearon para captar el apoyo de los sectores católicos, tanto en el interior como en el extranjero, así como la auténtica guerra de propagandas se vivió en la Península Ibérica años después entre EE.UU., Gran Bretaña y Alemania, y que tuvo como espada de Damocles la política religiosa que cada una de estas naciones decía practicar y

\footnotetext{
${ }^{1}$ GONZÁLEZ CALLEJA, Eduardo (2000): "Reflexiones sobre el concepto de Guerra Civil", Gladius XX, p. 306.

2 GARCÍA FERNÁNDEZ, Hugo: «Relatos para una guerra. Terror, testimonio y literatura en la España nacional», Ayer, n.o 76, 2009, pp. 143-176.
} 
defender. En este último aspecto tampoco caminaremos sobre campo yermo, ya que las obras del historiador Eduardo Ruiz Bautista aportan importante luz sobre los esfuerzos de los censores españoles para favorecer las publicaciones de cuño nazi ${ }^{3}$.

En nuestra última investigación ${ }^{4}$ retratamos detalladamente los organismos que se encargaron de la propaganda religiosa, tanto en la España republicana como en la franquista. De igual manera, pusimos de relieve la importancia que el aspecto religioso, bajo la forma de literatura propagandística, se había dando entre las potencias mundiales desde la Gran Guerra hasta el fin de la Segunda Guerra Mundial ${ }^{5}$. Bajo estas coordenadas se inscribían publicaciones como El Mundo Católico (semanario editado por la Embajada norteamericana en Madrid); Religion and the Reich; Bulletin of the Spiritues Issues of the War; Noticiario Católico Inglés o El Cruzado. Mensajero Católico Alemán. Pese al esfuerzo de síntesis que realizamos, no fuimos capaces de repasar las más relevantes producciones propagandísticas religiosas que países como Bélgica, Francia y Alemania impulsaron a raíz del conflicto hispano. Nuestro propósito es describir, analizar y contextualizar de manera exacta este género de escritos, intentando establecer rasgos comunes entre ellos, en especial el tipo de lenguaje que emplearon.

A modo de anticipo, subrayar que en la mayoría de obras el contrario era presentado como "enemigo de Dios". Para justificar la guerra se recurre (al menos desde la coalición insurgente) al término Cruzada y se habla de una lucha entre las fuerzas del Bien y del Mal. La guerra en este género de escritos es un combate entre unos "héroes", que cumplen un destino histórica sagrado versus a un oponente que representa todo aquello que es inmoral y despreciable, y al que se le atribuyen epítetos como impuro, inhumano, impío. Se acusa a la parte contraria de "asesinar a cristianos", de "crucificar los sagrado" 6 ... Las fuerzas rebeldes y los intelectuales extranjeros enfocaron sus odios al bolchevismo, mientras que desde el reverso

\footnotetext{
${ }^{3}$ Podemos destacar los siguientes títulos, Los señores del libro: propagandistas, censores y bibliotecarios en el primer franquismo. Gijón: Ediciones Trea, 2005; o el capítulo compartido con Pedro Barruso, "La propaganda alemana en España durante la segunda guerra mundial», en Moreno Cantano, Antonio César: El ocaso de la verdad. Propaganda y prensa exterior en la España franquista (1936-1945). Gijón: Ediciones Trea, 2011, pp. 191-214.

4 "Literatura de propaganda religiosa en España (1936-1945)", en MORENO CANTANO, Antonio César (coordinador): Cruzados de Franco. Propaganda y diplomacia en tiempos de guerra (1936-1945), Gijón, Editorial Trea, en prensa.

${ }^{5}$ A modo de ejemplo véanse, HENCH, John B. (2010): Books as weapons. Propaganda, publishing and the Battle for Global Markets in the Era of World War II, USA, Cornell University Press; BUITENHUIS, Peter (1987): The Great war of words. Literature as Propaganda, 1914-1918 and after, London, Bastford Ltd; CULL, Nicholas John (1995): Selling war. The British Propaganda Campaign Against American "Neutrality" in World War II, Oxford, Oxford University Press; o HOLMAN, Valerie (2008): Print for Victory. Book Publishing in England, 1939-1945, London, British Library.

${ }^{6}$ KEEN, Sam (1986): Faces of the enemy. Reflections of the Hostile Imagination, San Francisco, Harper and Row, pp. 18 y 27-29.
} 
político, el Mal estaba representado por el Fascismo. Sea como fuere, la caracterización del adversario se plagó de adjetivos despectivos y representaciones visuales cuya finalidad era borrar todo vestigio humano de su oponente, tal y como veremos a continuación.

\section{Literatura belga y francesa}

La Iglesia belga, encabezada por el primado Josef Ernest Van Roey, apoyó decididamente a la jerarquía eclesiástica española durante la Guerra Civil ${ }^{7}$. En febrero de 1937 patrocinó la obra Les évêques ont parlé. Les catholiques doivent souvenir la cause de Franco (Los obispos han hablado. Los católicos deben apoyar la causa de Franco), recopilación de cartas pastorales españolas. Este texto fue editado por el Bureau Universel de Presse (B.U.P.), que era un centro de propaganda profranquista fundado por el abad Vincent de Moor. Se trataba de una especie de adaptación de la Carta Colectiva del cardenal Gomá. Abría sus páginas con un breve prólogo de diez líneas del referido De Moor, en el que afirmaba a viva voz que "la lutte d’Espagne est une croissade, une guerre sainte". Meses antes, el cardenal Van Roey había hablado enérgicamente contra el peligro comunista en Directives au sujet du communisme et de certains courants d'idées en Belgique (25 de diciembre de 1936) ${ }^{8}$. Como recogían complacidas las autoridades rebeldes, Van Roey denunciaba que:

En España desde que se han apoderado los comunistas del gobierno de Madrid, la Guerra Civil, ya de suyo harta funesta, se recrudece como horrible guerra religiosa... Se extiende una orgía infernal de incendios de iglesias y de conventos, de asesinatos de obispos, de sacerdotes... con el exterminio sin piedad de las personas y cosas que representan la religión católica ${ }^{9}$.

Esta índole de obras se vieron respaldadas por la del aristócrata belga en Madrid, Alexandre van der Burch, Le Calvaire Ibérique, así como numerosos artículos en medios

\footnotetext{
${ }^{7}$ Sobre el posicionamiento de la Iglesia belga véase, entre otros trabajos, el de GROGNARD, Christian (1987): "Une guerre religieuse et patriotique. Positions d' un hebdomaire de droite: la revue catholique des idées et des faits", Revue Belgue d'Histoire Contemporaine, núm. 3/4, pp. 691-724.

${ }^{8}$ SAVAGE, Pierre (1987): "Le Groupe de La Cité Chrétienne face a la guerre d’Espagne", Revue Belgue..., op.cit., pp. 737-747.

9 "Recorte de prensa recogiendo declaraciones del primado de Bélgica a favor de la Carta Colectiva", 16 de enero de 1938, en GALLEGO, José Andrés y PAZOS, Antón M. (2009): Archivo Gomá. Documentos de la guerra civil, Vol. IX, pp. 97-99.
} 
como la Libre Belgique o Les Nouvelles de la Louvière, calificados por la máxima autoridad religiosa del país como "propagande pour la verité"10.

De Moor es un personaje de gran interés. Durante la Primera Guerra Mundial fue uno de los fundadores del diario patriótico clandestino, Libre Belgique. Bajo el apodo de "Lieutenant Marcel" actuó como responsable de una organización de espionaje dependiente del Servicio de Inteligencia belga. Pasó seis meses en España junto a las tropas rebeldes. Finalmente, en el tiempo de guerra mundial formó parte de los Servicios de Información de los Aliados. De su experiencia española nacieron La Question Basque et la Guerre Civile en Espagne (poco después de la toma de Bilbao en el verano de 1937) y L'horreur rouge en terre d'Espagne (1938). Esta obra, apelando a todas y cada una de las tesis del supuesto complot comunista, se caracteriza por un discurso casuístico (todos los hechos del pasado conducían al "desorden" de 1936) de la historia contemporánea de España. Se enumera múltiples causas que, tras su debida argumentación, conducen a la "acción salvadora" del golpe militar del 18 de julio, el cual hizo frente al supuesto peligro de la desaparición de los valores tradicionales del país:

N'est plus question d'insurrection mai d'obéissance à l'instinct de conservation qui nos soutient dans nostre juste revendication du plus imprescriptible des droits, le respect des biens et des persones.

La guerre dans ces circonstances n'est pas seulement légitime et permise: elle est sainte et glorieuse ${ }^{11}$.

El componente religioso de la Guerra Civil (el bando nacional no dejó de reivindicar que se trataba de una guerra santa, trascendiendo el simple ejercicio retórico de legitimación ${ }^{12}$ ) era puesto en primer plano al resumir todas las razones que "reclamaban" un cambio de rumbo político, social y económico en España: 1) "Les églises, les oeuvres d'art flambaient"; 8) "La persécution anticléricale sévissait"; 10) "Le petit clergé était réduit a la famine..." ${ }^{13}$. Y a estas grandes conclusiones acompañaba una minuciosa lista de todos los atentados que la Iglesia española sufrió en los primeros meses de 1936, apoyándose para ello en la Revue de Paris de octubre de ese año ${ }^{14}$. El autor incide, una y otra vez, en los "planes" de la Franc-masonería internacional para situar a la Península Ibérica bajo la égida de Stalin ("Staline était roi

\footnotetext{
${ }^{10}$ BENIT, André (1996): La guerre civile espagnole dans la littérature belge: Paul Nothlomb: histoire, romans et mythe, Madrid, Universidad Complutense de Madrid, p. 136.

${ }^{11}$ MOOR, Vincent de (1938): L'horreur rouge en terres d'Espagne, Bruxelles, B.U.P., p. 125. El subrayado es nuestro.

${ }^{12}$ Es la tesis defendida por Mary Vincent (2007): "La Guerra Civil española como Guerra de Religión", Alcores. Revista de Historia Contemporánea, núm. 4, pp. 64-66.

${ }^{13}$ MOOR, Vincent de (1938): L'horreur rouge..., op. cit., p. 119.

${ }^{14}$ Ibidem, p. 10.
} 
del régime de terreur"), ayudado por sus "secuaces" republicanos: Largo Caballero ("un Lénine réincarné") o Azaña ("ouvrier maçon") 15 .

Su máxima preocupación es evitar el "contagio"16 del mal español al resto de países europeos, en especial a Francia, donde -según su criterio- se estaba gestando una revolución por la acción conjunta de Inglaterra, del bolchevismo internacional y del anticatolicismo practicado por diferentes dirigentes galos como Clemenceau ${ }^{17}$.

En las antípodas ideológicas y de razonamiento se encontraba Le drame de L'Espagne de Georges Hoog. Redactor jefe del diario del partido, La Jeune République ${ }^{18}$ y firme valedor del Frente Popular en España, fue uno de los firmantes -junto a ilustres nombres como François Mauriac, Jacques Maritain o Luigi Sturzo- del manifiesto "Pour le peuple Basque. Un appel à tous les hommes de coeur", promovido por el Padre Alberto Onaindia ${ }^{19}$ contra los bombardeos de Guernica en $1937^{20}$. Hoogs, como indica el subtítulo de su trabajo, Croisade morale ou Guerre Sociale?, defiende un planteamiento que echa por tierra el revestimiento sagrado del conflicto español, tan del gusto del bando franquista y del episcopado peninsular. Sin desdeñar la importancia del factor religioso, advierte que lo que acontece en España "n'est pas une croisade antibolcheviste" ${ }^{\prime 21}$. $\mathrm{Y}$ para demostrarlo recurre a los datos y testimonios publicados en multitud de medios periodísticos católicos, como La Vie intellectuelle, Etudes (de los jesuitas), La Terre Wallone (de los católicos belgas), Esprit o La Croix. Su tesis principal era que la causa fundamental de la guerra obedecía al atraso social, económico y cultural que vivía el país por culpa de la opresión de los grupos conservadores coaligados con la Iglesia. Recoge diferentes estadísticas de la época que ponían en boga que un $0,35 \%$ de los grandes propietarios poseía nueve millones de hectáreas frente a los cinco millones que pertenecían al resto de la población ${ }^{22}$.

\footnotetext{
${ }^{15}$ Ibidem, pp. 54 y 60.

16 En la propaganda fascista, el tema del marxismo y el bolchevismo como algo infeccioso y extremadamente peligroso fue muy recurrente y promocionado. En una investigación en ciernes analizamos esta idea a partir de las exposiciones de signo anticomunista que países como Alemania (Das Sowjet-Paradies, en castellano "El Paraíso Soviético", mayo-junio de 1942), Francia (Le Bolchevisme contre l'Europe, 1942) o España (Así eran los rojos, 1943), impulsaron desde la invasión de la URSS en junio de 1941.

${ }^{17}$ MOOR, Vincent de (1938): L'horreur rouge..., op. cit., p. 17.

${ }^{18}$ En 1931 escribió la obra Histoire, doctrine, action de la Jeune-République.

${ }^{19}$ Sobre este importante personaje, CAL, Rosa (2012): "Onaindia: propagandista contra el franquismo", Miguel Hernández Communication Journal, no 4, 2012, pp. 11-36.

${ }^{20}$ SOUTHWORTH, Herbert R. (1977): Guernica! Guernica! A study of Journalism, Diplomacy, Propaganda and History, Berkeley, University of California Press, pp. 149-150. Esta obra, de la que ya existía traducción al castellano, ha sido reeditada en 2013 por la Editorial Comares añadiéndole un excelente estudio del profesor Ángel Viñas.

${ }^{21}$ HOOGS, Georges (1937): Le drame de l'Espagne. Croisade morale ou Guerre sociale?, París, La JeuneRépublique, p. 9.

22 Ibidem, p. 12.
} 
Apelando a las palabras del periodista de Etudes, M. Marc Le Mondégue, explicaba que "L'organisation économique et sociale des provinces entières du sud de l'Espagne est encore un régime strictement féodal ${ }^{23}$. A ello había que sumar el enorme analfabetismo que, como evidenció el ministro de Instrucción Pública de Portugal, M. Antonio Sergio de Sousa, representaba el $65 \%{ }^{24}$. A partir de este tipo de cifras, Hoogs señalaba que la jerarquía eclesiástica condenaba a la Segunda República no por su política religiosa sino por haber apartado del poder a los partidos conservadores, que eran los que habían garantizado hasta 1931 su status privilegiado, sin importarles las desigualdades económicas y sociales que sufrían la mayor parte de la población ${ }^{25}$. Finalizaba su escrito criticando duramente el escaso interés por la justicia social del episcopado español, que en vez de ser una "fuerza espiritual y moral" se había convertido en una "fuerza de división y de odio que había ensangrentado la patria" 26. Tanto en Vincent de Moor como en Hoogs se hace referencia -ya sea para criticar o exaltar- a diferentes sacerdotes españoles (por ejemplo, José Manuel Gallegos Rocafull ${ }^{27}$ ), que no comulgaron con los postulados imperantes en la jerarquía eclesiástica y que se opusieron decididamente a la coalición golpista y al concepto de cruzada para definir la guerra española ${ }^{28}$.

Uno de estos religiosos disidentes y que tuvo un peso destacado en Francia fue Iñaki de Azpiazu, que utilizó a lo largo de su vida los pseudónimos de "Iñaki de Aberrigoyen" o "J. de Hiriartia" para redactar algunas de sus obras. Exiliado al país vecino en abril de 1937, actuó como capellán del "Comité Católico de Ayuda a los refugiados españoles". Al estallar la Segunda Guerra Mundial se dedicó a asistir a los perseguidos por la Gestapo $^{29}$. Uno de sus escritos más importantes, traducido -en primer lugar- al francés, al inglés, al castellano y al alemán fue Le Cas des Catholiques Basques (1938). A lo largo de cincuenta páginas, el autor (que utiliza en esta ocasión el sobrenombre de "J. de Hiriartia") comenta el posicionamiento de los católicos vascos durante el tiempo de la Segunda República y la Guerra Civil, combatiendo paralelamente la acusación de que no han querido unirse a las derechas españolas en su lucha contra el comunismo, lo

\footnotetext{
${ }^{23}$ Ibidem, p. 13. El subrayado es nuestro.

${ }^{24}$ Ibidem, pp. 14-15.

${ }^{25}$ Ibidem, p. 21.

${ }^{26}$ Ibidem, p. 66.

27 Mientras escribimos estas líneas se acaba de publicar una biografía sobre el mismo firmada por CASAS, José Luis (2013): Por lealtad a la República. Historia del canónigo Gallegos Rocafull, Barcelona, Editorial Base.

${ }^{28}$ El estudio más elaborado sobre esta cuestión, que refleja que lejos de constituir un grupo religioso minoritario tuvo un peso más relevante de lo que se creía, es el de MONTERO, Feliciano, MORENO CANTANO, Antonio César y TEZANOS, Marisa: Otra Iglesia. Clero disidente durante la II República y la Guerra Civil, Gijón, Trea (en prensa).

${ }^{29}$ Véase, www.euskomedia.org o su obra 7 meses y 7 días en la España de Franco. El caso de los católicos vascos, Caracas, Ediciones Gudari, 1946.
} 
que les convertía implícitamente en defensores del mismo ${ }^{30}$. En su contestación, se nos presenta -a la par- como un firme valedor del episcopado español, puesto que incide en más de una ocasión que en las encíclicas de 1931 y 1932 (sobre todo por impulso del cardenal Vidal i Barraquer) llamaba a la aceptación del orden establecido, todo lo contrario que las derechas (lo que a su vez agrandaba las diferencias con el modo de actuar de los vascos). Para demostrarlo utiliza, una y otra vez, declaraciones de destacados dirigentes conservadores españoles (Lamamié de Clairac, Calvo Sotelo, Gil Robles) y de sus medios periodísticos afines ( $A B C$, El Siglo Futuro). Frente a esta postura de ruptura y provocación, el lehendakari José Antonio Aguirre abjuraba de la sedición y la rebelión por no ser armas propias de un cristiano ${ }^{31}$. La tensión entre el Gobierno vasco y los partidos conservadores se hizo -prosiguiendo con el relato del autor- a partir de 1933 y tuvo como punto de desencuentro máximo la cuestión de la autonomía y el Estatuto vasco ${ }^{32}$. Este odio cristalizó con el golpe militar del 18 de julio del 36, considerado en este opúsculo "comme illicite la rébellion armée de Franco" ( $p$. 34), y en el que en "nom de Dieu et au nom d'une Croisade religieuse" se ha perseguido y asesinado a miles de católicos vascos (p. 36). ¿Su delito? "Ser culpables de respetar la República, de condenar la violencia, de promover la justicia social republicana y defender las libertades vascas". En el capítulo final se quería dejar constancia que la Iglesia que había firmado la Carta Colectiva de 1937 no representaba al pueblo vasco, ya que ésta servía a Franco y no al espíritu cristiano (p. 43).

\section{Literatura religiosa nazi sobre la Guerra Civil española}

La historiografía alemana ha mostrado en las últimas décadas un interés mayúsculo por la literatura de propaganda que el Tercer Reich impulsó a raíz de la Guerra Civil española. Diferentes autores, ya sea en alemán o inglés, como Peter Monteath ${ }^{33}$, Christoph Eykman ${ }^{34}$ o Antonio Peter ${ }^{35}$, nos ofrecen en sus investigaciones un

\footnotetext{
${ }^{30}$ HIRIARTIA, J. de (1938): Le Cas des Catholiques Basques, París, Chez H. G. Peyre, p. 5.

31 Ibidem, p. 17.

32 Para ilustrar este aspecto, el Padre Iñaki reproduce las palabras del político Calvo Sotelo en un mitin de 1935 en el que declaró: "Prefiero una España roja que una España desmembrada".

33 MONTEATH, Peter y ELKE, Nicolai (1986): Zur Spanienkriegsliteratur. Die Literatur des Dritten Reiches Zum Spanischen Bürgerkrieg, Frankfurt am Main, Verlag Peter Lang; o Writing the Good Fight: Political Commitment in the International Literature of the Spanish Civil War, Greenwood Press, 1994.

${ }^{34}$ EYKMAN, Christoph (1992): "The Spanish Civil War in German Publications during the Nazi Years", en COSTA, Luis et alli: German and International Perspectives on the Spanish Civil War: the Aesthetics of Partisanship, Columbia, Candem House, pp. 166-178.
} 
panorama detallado de los principales títulos que, relacionados con el conflicto español, circularon dentro de las fronteras alemanas. Nos explican las razones del interés de la maquinaria propagandística nazi por España y las peculiaridades lingüísticas e ideológicas de este tipo de publicaciones. En castellano, el único trabajo de renombre sobre este género de literatura se lo debemos a Stefanie SchülerSpringorum, que en un brillante artículo analizó los estereotipos o imágenes que desde estos folletos, libros y opúsculos se daba de la guerra en España en la propaganda germana $^{36}$. La atención sobre esta cuestión, lejos de decaer, ha sido revitalizada de nuevo gracias a los investigadores germanos Bettina Bannasch ${ }^{37}$ y Wolfgang Asholt ${ }^{38}$. Merced a todo este legado historiográfico hemos podido conocer diferentes obras cuyo temática preferente -siguiendo con el hilo conductor de esta investigación- era la persecución religiosa. Nos detendremos en cuatro títulos: Das Rotbuch über Spanien (El Libro Rojo sobre España), Christen im Spanischen Sturm (Cristo en la tormenta española), Die Wahrheit über Spanien (La verdad sobre España) y Schwarzbuch über Spanien (El Libro Negro sobre España).

Previamente a su estudio nos adentraremos en los elementos comunes de partida y la significación que esta clase de literatura tuvo dentro de la ideología nazi en los años previos a la contienda mundial. En 1933, por impulso de Josef Goebbels, se había constituido la Unión de Agrupaciones Anticomunistas Alemanas, más conocida como la Antikomintern. Entre sus cometidos, que debía actuar en consonancia con su precedente inmediato europeo, es decir, la Entente Internationale Anticommuniste $(E I A)^{39}$, estaba la lucha contra la propaganda y las actividades de la Tercera Internacional en todo el mundo. Desde un primer momento, como ha demostrado el profesor Jesús de la Hera ${ }^{40}$, la España republicana fue considerada como una víctima más del tentáculo comunista. Cuando se produjo el levantamiento militar, todos los

\footnotetext{
35 PETER, Antonio (1992): Das Spanienbid in den Massenmedien des Dritten Reichen, 1933-1945, Frankfurt am Main, Peter Lang.

36 "Las representaciones de la violencia en la Guerra Civil española: el ejemplo alemán", Alcores, n. 4, 2007, pp. 39-54.

${ }^{37}$ Erimern und erzählen: der Spanische Bürgerkrieg in der deutschen und spanischen Literatur und in den Bildmedien, Tübingen, Gunter Narr Verlag, 2005.

38 España en el corazón: der Spanische Bürgerkrieg. Medien und Kulturelles Gedächtniss, Bielefeld, Aisthesis, 2008.

${ }^{39}$ Uno de sus departamentos más trascendentes fue el "Comité Pro Deo", que durante la Guerra Civil editó títulos como Nos frères catholiques sous la Croix en Espagne. Véanse, CAILLAT, Michel (2007): "L' Entente internationale anticommuniste, 1924-1939. Lorsque Genève était la capitale mondiale de I'anticommunisme", Solidarités, Cahiers émancipations, n. 110, pp. 1-4 ; y ROULIN, Stephanie (2010): Un credo anticommuniste. La Comisión Pro Deo de l'Entente internationale anticommuniste ou la dimension religieuse d'un combat politique (1924-1945), Lausanne, Éditions Antipodes, 2010.

40 DE LA HERA MARTÍNEZ, Jesús (2002): La política cultural de Alemania en España en el periodo de entreguerras, Madrid, CSIC.
} 
esfuerzos del Ministerio de Propaganda de Goebbels (Promi) ${ }^{41}$ se volcaron en presentar este incidente en la Península Ibérica como un asunto de materia nacional, ya que la lucha contra el comunismo no entendía de fronteras. Los alemanes fueron convencidos de que la Guerra Civil española era la prueba más evidente de las intenciones bélicas de la Unión Soviética. Se trataba de una batalla entre las fuerzas del Bien y del Mal. Franco y sus aliados (Alemania e Italia) se habían embarcado en una cruzada para salvar a la civilización occidental de las "garras" del bolchevismo y el judaísmo. Esto implicaba que Franco era el líder legal y legítimo del Gobierno español. Por tanto, los términos "rebelde" y "fascista" tenían que ser eliminados de las publicaciones alemanas y ser sustituidos por el de "Nacionales" 42.

Decenas de obras aparecieron en el Tercer Reich desde 1936 que siguieron estas directrices y construyeron una imagen monstruosa y maléfica del enemigo: el "rojo", asimilado con el comunista, el judío... Se desarrolló una auténtica literatura del terror sobre la España republicana, en la que se torturaba a los religiosos, se bombardeaba a la población civil... Fue la tónica dominante en publicaciones como Viva España! Arriba España! Eine Frau Erlbt den spanischen krieg, de María de Smeth; Blutender Sommer (Verano Sangriento), de Hans Roselieb; Die Letzten Reiter (El Último Jinete), de Edwin E. Dwinger ${ }^{43}$ o Hier spricht spanien, del filólogo y canónigo español, a la postre catedrático de Filología Griega en la Universidad de Barcelona, Sebastián Cirac Estopañán, que describió la destrucción de los valores cristianos y de la Familia durante el periodo republicano ${ }^{44}$. La función de toda esta propaganda era muy importante: la preparación psicológica de la población alemana para la guerra. En esta ocasión los combates tenían lugar lejos del Reich, pero un enfrentamiento mayor como profetizaba Goebbels- se esta incubando contra el bolchevismo internacional ${ }^{45}$. Para lograr la cohesión interna la receta empleada fue servirse del lenguaje de la antítesis y de la política de atrocidades, tal y como sería muy frecuente a partir de $1939^{46}$. Se empleaba en todo este tipo de propaganda un "lenguaje cerrado", que se servía de un valor (el Bien, la moral, la paz) para justificar otro (el Mal, la inmoralidad,

\footnotetext{
${ }^{41}$ La literatura sobre este organismo es muy abundante. A modo de ejemplos citaremos el ya clásico trabajo de ZEMAN, Z.A.B. (1973): Nazi Propaganda, Londres, Oxford University Press; y el más reciente de, KALLIS, Aristotle, A. (2005): Nazi Propaganda and the Second World War, Palgrave McMillan.

42 MONTEATH, Peter (1994): Writing the Good Fight..., op. cit., p. 25.

${ }^{43}$ SCHÜLER-SPRINGORUM, Stefanie (2007): "Las representaciones de la violencia...", op. cit., p. 268.

${ }^{44}$ Sobre esta obra y su autor véanse, PETER, Antonio (1992): Das spanienbild in den Massenmedien..., op. cit., pp. 115-116; o DE LA HERA MARTíNEZ, Jesús (2002): La política cultural de Alemania..., op. cit., pp. 351-355.

${ }^{45}$ MONTEATH, Peter (1994): Writing the Good Fight..., op. cit., p. 27.

${ }^{46}$ En septiembre de ese año, con la invasión de Polonia como telón de fondo, y para ganarse a la opinión pública, se publicitaron supuestos ataques sobre minorías étnicas alemanas en ciudades como Bydgoszcz, que teóricamente se cobraron más de seis mil muertos. LUCKERT, Steve y BACHRACH, Susan (2011): State of Deception. The power of Nazi Propaganda. Washington, 2011, pp. 104-105.
} 
la guerra, el asesinato). Prevalecieron fórmulas del tipo "o esto o lo otro", por ejemplo: "con los judíos es imposible pactar, sólo atenerse a una viril alternativa", "Alemania o será una potencia mundial o no será absolutamente nada" 47 . Pronto esta retórica, de clara inspiración germana, fue asimilada por los ideólogos franquistas, que en sus publicaciones advertían que "el Soviet impone una causa antipopular y odiosa: el robo de niños, la muerte por hambre y el régimen de terror" mientras que su causa "despierta ecos de admiración en el mundo entero" 48 . Como comentamos en párrafos anteriores, lo que se pretendía con esta clase de literatura era atemorizar a la población, lograr la adhesión internacional (ya fuese en España o en Alemania) y legitimar el recurso a la violencia mediante la demonización del adversario ${ }^{49}$.

Todos estos ingredientes, más un rico y llamativo material gráfico, se conjuntaron en la obra Das Rotbuch über Spanien. Bilder, Dokumente, Zeugenaussagen. Fue publicada en 1937 (año prolífico en publicaciones, no en vano fue en esa fecha cuando se produjeron las protestas internacionales por el bombardeo de Guernica) por la Antikomintern y presentada a bombo y platillo en la prensa española, ya que "contiene interesantes documentos y revelaciones sobre la política desarrollada por la Rusia soviética en España, para demostrar la ingerencia rusa en la guerra española" ${ }^{50}$. Más negativo, como es de suponer, es el juicio que ha recibido en la actualidad por los especialistas sobre el tema, que la han calificado como "una publicación propagandística de la peor calaña" ${ }^{51}$. Como indica la historiadora Stefanie Schüler, se trataba de fotografías y documentos falsificados previamente utilizadas por Goebbels en un acto del NSDAP ${ }^{52}$. Independientemente de estas circunstancias y de la opinión que nos genere, su valor propagandístico durante la guerra está fuera de toda duda. Escritos como el del sacerdote catalán Luis Carreras, Grandeza cristiana de España. Notas sobre la persecución religiosa (1938), recurren de manera reiterada a muchas de las ideas contempladas en Das Rotbuch, ya sean los episodios de violencia anticlerical en el campo republicano o a las polémicas declaraciones de "religiosos apóstatas" en Heraldo de Madrid ${ }^{53}$. Con todos estos antecedentes sobre la palestra, procedamos al

\footnotetext{
${ }^{47}$ LUTZ, Winckler (1979): La función social del lenguaje fascista, Barcelona, Ariel, p. 60.

48 Servicio Antimarxista, boletín n.o 16, 1 de octubre de 1938 y Boletín Decenal Informativo de la Delegación Nacional del Servicio Exterior de Falange, n.o 16, 20 de julio de 1938.

49 SEVILLANO CALERO, Francisco (2007): Los rojos. La representación del enemigo en la Guerra Civil, Madrid, Alianza Editorial; y GARCÍA FERNÁNDEZ, Hugo (2009): "Relatos para una guerra. Terror, testimonio y literatura en la España nacional", Ayer, n.ㅇ 76, 2009, pp. 143-176.

${ }^{50} A B C, 26$ de junio de 1937.

51 SCHULZE SCHNEIDER, Ingrid (2001): "Josef Goebbels, 'historiador' de la Guerra Civil española", Historia y Comunicación Social, n.ำ 6, p. 51.

52 SCHÜLER-SPRINGORUM, Stefanie (2007): "Las representaciones de la violencia...", op. cit., p. 43.

53 Sobre este asunto véase, TOLL, Gil (2013): Heraldo de Madrid. Tinta catalana para la II República Española, Sevilla, Editorial Renacimiento.
} 
estudio de los aspectos más relevantes de este título ${ }^{54}$. El origen del mismo arranca en septiembre de 1936, tras el impulso de una nueva campaña difamatoria contra la URSS. Esta premisa determinó la línea temática a seguir a lo largo de sus 319 páginas. No se trataba de escribir sobre la "España Nacional" de Franco ni de las "acciones heroicas" de la Legión Cóndor, sino de plasmar de la manera más directa y cruda posible (mediante supuestos documentos, testimonios reales y fotografías de gran impacto) a la "Rotspanien" (la España Roja). El argumento era simple y repetitivo: 1) Los comunistas eran los culpables de la guerra en España ("ninguna constitución democrática puede engañarnos sobre la presencia de una dictadura judeobolchevique en la España roja", p. 211) y 2) La democracia y el comunismo tenían como objetivo final acabar con el pueblo alemán.

A partir de estos enunciados básicos, un equipo de especialistas del ministerio de Goebbels tenía que montar toda su parafernalia propagandística. De los diferentes autores (encargados de documentación, comentarios y fotos) encontramos a Alfred Gielen y E.H. Bockhoff, que a partir del éxito conseguido por El Libro Rojo colaboraron en nuevas obras sobre el comunismo ${ }^{55}$. En primer lugar, se nos explicaba el origen del bolchevismo internacional en la Península Ibérica a partir de una reunión de la Confederación Nacional de Trabajadores (CNT) en 1919. Después, se realizaba un particular repaso histórico hasta llegar a la guerra y al "Terror Rojo" (Roten Terror). Buena parte de la obra se compone de abundantes fotomontajes que "demostraban" los más horrendos crímenes del bando republicano. Se nos ofrece sin ningún tipo de censura cadáveres mutilados, quemados y descompuestos. Retratos de los responsables de dichas acciones bajo el epíteto de "asesinos insaciables" (pp. 101112). Es palpable en estas imágenes (por más que se hallase en una línea totalmente frontal y opuesta al Tercer Reich) la influencia del artista dadaísta John Heartfield, que empleaba la fotografía como una provocación, como se puede observar en sus más famosos fotomontajes ridiculizando a Hitler ("Adolf, el superhombre, traga oro y vomita basura") o enarbolando la resistencia republicana frente a la agresión de las potencias extranjeras ("No pasarán, Madrid 1936", donde unos enormes buitres, caracterizados con los símbolos del ejército nazi y franquista, junto a unas gigantescas bayonetas se ceñían amenazantes sobre la capital española) ${ }^{56}$.

\footnotetext{
54 Los datos más destacados serán extraídos de la propia obra así como de las investigaciones de Eykman y Monteath.

55 En 1937 Bockhoff escribió Völker-Recht gegen Bolchewismus (Derecho Internacional contra el Bolchevismo) y Gielen en 1939 elaboró el Memorándum sobre la interferencia del bolchevismo y las democracias en España.

56 Sobre los fotomontajes del artista alemán véase, MAYOR FERRÁNDIZ, Teresa M.a (2011): "John Heartfield, un artista antinazi", en Revista de Claseshitoria. Publicación digital de Historia y Ciencias Sociales, n. 190.
} 


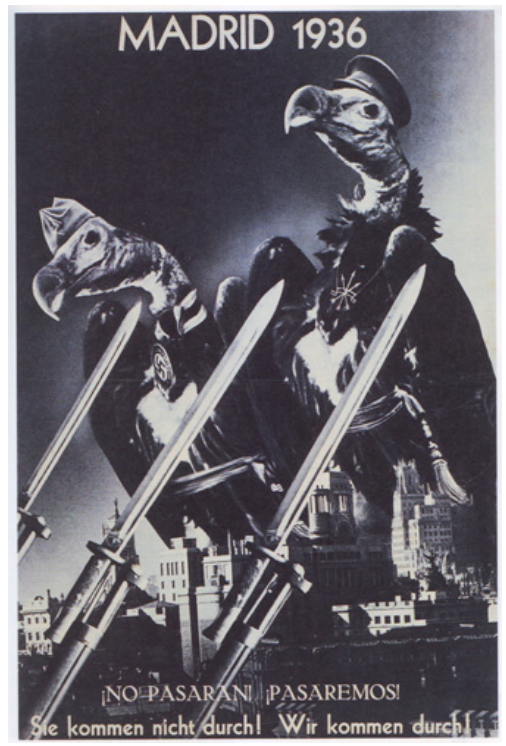

Fotomontaje de John Heartfield sobre la Guerra Civil

El tema religioso también está muy presente, si bien ofrece una dimensión ambigua. Junto a imágenes de destrucción de iglesias o de profanación de símbolos sagrados, se llega a criticar "el desafortunado y reaccionario rol que la Iglesia y la política clerical habían jugado en la vieja España". En definitiva, El Libro Rojo sobre España intentó promocionar una visión anticomunista de la guerra peninsular, apelando a los sentimientos más profundos del lector, que había sido bombardeado desde hacía años por la propaganda nazi con una serie de prejuicios y estereotipos sobre el mundo que les rodeaba.

El gran artífice de este plan -como ya se ha dicho- fue Goebbels, que en 1937 dio un famoso discurso en Nuremberg sobre la Guerra Civil, editado posteriormente en forma de folleto (36 páginas) bajo el encabezamiento de Die Wahrheit über Spanien (La Verdad sobre España). Se englobaba dentro de aquella categoría de obras bajo la denominación anglosajona de "The truth about Spain" (por ejemplo, la del británico H. R. Greaves de 1938) y que pretendía establecer de forma definitiva el "verdadero" sentido del conflicto hispano. La repercusión de las palabras del ministro de Propaganda fue enorme, siendo reproducidas en multitud de rotativos internacionales como el Daily Mail, The Times, Jour e incluso los diarios soviéticos Pravda e Izvestia. Se vuelve a echar mano de los repetidos conceptos e ideas de la conspiración judeobolchevique, al caos y a la anarquía en suelo republicano, al peligro del contagio del comunismo en caso de triunfar en España y, por supuesto, a la persecución religiosa, de las que se nos dan numerosos ejemplos:

Un fugitivo sueco dice el 10 de octubre de 1936: "He visto iglesias que tenían las paredes cubiertas con cuerpos de mujeres, monjas decapitadas o quemadas puestas en filas en las paredes de la iglesia... Vi el asesinato de monjas y curas y 
una horda de 50 hombres que procedían bestialmente con las mujeres. Cinco monjas de más de 70 años que vivían frente al consulado inglés fueron sacadas por una horda de comunistas, las llevaron con ellos y las asesinaron"57.

Como se aprecia en este fragmento, así como en otros ejemplos expuestos, el contrario, el odiado, siempre es retratado como un personaje anónimo, que forma parte de un colectivo, en este caso la "horda", lo que facilita su rechazo por parte del ciudadano de a pie, ya que no se rechaza o se excluye a una persona en concreto, sino a todo un grupo, en este caso los comunistas, asimilados con el asesinato, la profanación, la inhumanidad.

Para finalizar con los folletos nazis que incidieron en el aspecto religioso de la guerra nos ocuparemos de Christen im spanischen Sturm (1937), del Dr. Heinrich Baldauf, ingeniero, que en 1934 había redactado un texto sobre la lucha periodística en la región del Sarre. La mayoría de sus páginas ponen el punto de mira en la "persecución roja" sobre los católicos (die Verfolgung). Baldauf comienza explicando la historia de España en clave cristiana, con especial atención a la Edad Media, resaltando las conquistas de Toledo, Valencia, Sevilla hasta llegar a Granada en 1492. Saltamos posteriormente hasta la Guerra de la Independencia, pasamos por la Semana Trágica (1909) y finalizamos en el periodo republicano. El elemento común de todo este periodo sería la unidad cristiana ante los peligros exteriores: los musulmanes, los franceses hasta llegar al bolchevismo soviético ${ }^{58}$. En el capítulo once (pp. 18-33) se dan múltiples datos sobre los martirios $\mathrm{y}$ asesinatos perpetrados por los milicianos republicanos, a partir de la versión de diferentes sacerdotes, obispos y periódicos. Se recogen declaraciones del cardenal Gomá y se resalta en letra negrita que estábamos ante una guerra religiosa ("Religionskrieg"). Un aspecto bastante original del libro es el recurso a la caricatura como elemento propagandístico ${ }^{59}$. Todas estas ácidas ilustraciones están extraídas del "diario rojo" Solidaridad Obrera y en ellas se ataca directamente a la jerarquía eclesiástica. Junto a estos dibujos se incluyen varias fotografías de gran brutalidad, como la de un cadáver masacrado y abandonado en las calles de Lora del Río (Sevilla); instrumentos de tortura; o multitud de cuerpos sin vida y mutilados en Talavera de la Reina (Toledo) antes de la entrada de las tropas nacionales. Para acabar se reproducía un fragmento de la encíclica Divinis Redemptoris del papa Pío XI.

\footnotetext{
${ }^{57}$ GOEBBELS, Josef (1937): La verdad sobre España. Discurso pronunciado en Nuremberg en el Congreso Nacional del Partido en 1937, pp. 20-21.

${ }^{58}$ BALDAUF, Heinrich (1937): Christen im spanische Sturm. Tatsachenberichte zur Verfolgung der Kirche in Spanien, Saarbrücken, Saarbrücken Druckerei und Verlag AG, pp. 7-17.

${ }^{59}$ Sobre este aspecto véase el monográfico de DÍAZ-PLAJA, Fernando (1980): La caricatura española en la Guerra Civil, dentro de la revista Tiempo de Historia, n.o 73.
} 
No queremos concluir esta investigación sin mostrar la cruz de esta propaganda germana de orientación religiosa. La respuesta a la misma nos la ofrece la obra Schwarzbuch über Spanien (Libro negro de España) del periodista alemán Arthur Koestler. Ante la imposibilidad de acudir a la versión original, hemos optado por la traducción francesa, L'Espagne ensanglantée: un livre noir sur l'Espagne, en la que se denuncian las "atrocidades fascistas". Este tipo de declaraciones provocaron que fuese detenido, durante el desarrollo de su trabajo como reportero durante la guerra, durante más de seis meses por las autoridades franquistas ${ }^{60}$. Lo más conocido de este escrito son las numerosas fotografías de niños sin vida como consecuencia de los bombardeos franquistas sobre Madrid, muchas de los cuales sirvieron al Gobierno republicano para ganarse la solidaridad internacional.

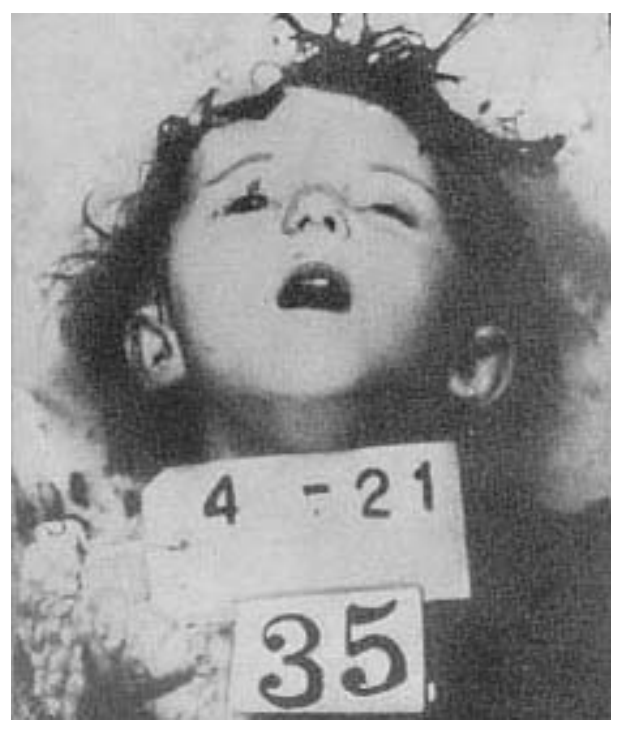

Una de las más famosas imágenes recogidas por Arthur Koestler

\section{Conclusiones}

La proliferación de libros propagandísticos nacionales y extranjeros acerca de la dialéctica irreconciliable entre católicos y ateos desde los primeros meses del conflicto armado peninsular se enmarca dentro de una interpretación religiosa del mismo. Pese a los esfuerzos que realizó el Gobierno republicano desde mediados de 1937 por presentar una situación de normalidad religiosa en sus fronteras (nombramiento del católico vasco Manuel Irujo como ministro de Justicia; restablecimiento del culto o el

\footnotetext{
60 Sobre su figura véanse, AMAR, Hanania A. (2011): Arthur Koestler. La rage antitotalitaire, París, L'Harnattan; o COLE, Sarah (2012): At the Violent Hour: Modernismo and Violence in England and Ireland, New York, Oxford University Press, especialmente pp. 217-221, donde se analizan las polémicas imágenes que incluyó en Schwarzbuch sobre los bombardeos aéreos de Getafe en noviembre de 1936.
} 
nombramiento del sacerdote Leocadio Lobo como responsable de Asuntos Religiosos), los desmanes de las fuerzas populares en Barcelona o en Madrid contra iglesias, conventos y monasterios... generaron un gran rechazo entre el catolicismo mundial. De inmediato, todos estos incidentes fueron propagados con gran ímpetu por el episcopado español, con publicaciones y pastorales como El Caso de España, ¿Qué pasa en España? o, en el verano de 1937, La Carta Colectiva de los obispos españoles. Sin embargo, el campo ganado hasta ese momento fue de inmediato perdido como consecuencia de los bombardeos sobre la sacrosanta ciudad vasca de Guernica. No es de extrañar que a partir de este suceso la propagandística extranjera aunase esfuerzos por restar importancia al mismo o criticarlo con todas sus fuerzas. Los temas y conceptos explotados en este género de propaganda religiosa recurrían siempre a la antítesis entre la supuesta conspiración judeomasónica-bolchevique y al asesinato de religiosos frente a la agresión fascista que perseguía y eliminaba a los católicos vascos, y que se apoyaba en la Iglesia para oprimir al pueblo. No solo eso. Pues este tipo de literatura también se interpretó en clave interna para lograr la adhesión de la población frente al enemigo exterior, ya fuese el comunismo o el fascismo. Era imprescindible apelar a las emociones más profundas y enraizadas, lo que se podía conseguir con imágenes y fotomontajes de gran violencia y brutalidad sobre los asesinatos y holocaustos que por motivaciones religiosas se daba en cada uno de los dos bandos confrontados.

Regresando a las principales iniciativas propagandísticas religiosas puestas en marcha por la España republicana y nacional se abren dos interrogantes: ¿hubo muchas diferencias conceptuales y tácticas en la literatura propagandística de ambos bandos? $Y$ en caso de responder afirmativamente, ¿cuáles fueron? Además, aparece otra cuestión aún más importante, ¿̇hubo algún vencedor -en el caso de poder ponderarlo cuantitativamente- en esta guerra religiosa de ideas? Analizamos al hablar de las Oficinas Católicas de Información Internacional que el lenguaje empleado en sus publicaciones pecaba de un exceso de negativismo, que buscaba la reafirmación de sus argumentos mediante la negación de los del adversario (antítesis). Este "defecto" también se repitió en el campo republicano, en especial durante la etapa de Largo Caballero como responsable del Gobierno ${ }^{61}$. Tras su sustitución por José Giral (mayo de 1937) y el nombramiento del católico vasco, Manuel de Irujo, como nuevo ministro de Justicia ${ }^{62}$, la política de atrocidades fue perdiendo fuerza, aunque siguió planteando confrontaciones en el seno de la Oficina Católica de París entre Juan Vicens y Ossorio y Gallardo, más proclive a la línea dura y dramática. Era más conveniente, según los

\footnotetext{
${ }^{61}$ RAGUER, Hilari: La espada y la cruz. La Iglesia, 1936-1939. Barcelona: Editorial Bruguera, 1977, pp. 161-162.

62 MARGENAT PERALTA, José M.: «Manuel de Irujo: la política religiosa de los gobiernos de la República en la guerra civil (1936-1939)», Cuadernos de Historia Moderna y Contemporánea, 4, Madrid, Universidad Complutense de Madrid, 1983, pp. 175-193.
} 
datos que manejaba la diplomacia republicana en el exterior, ofrecer una imagen de normalidad y legalidad. Los informadores de Burgos también fueron conscientes del perjuicio a nivel propagandístico de esta propaganda "apocalíptica". Es el caso, por ejemplo, de la sociedad americana, donde Rusell Palmer, responsable de la Peninsular News Services advertía a sus superiores que los ciudadanos de su país reclamaban una propaganda positiva, que incidiese en «la tarea constructiva que se lleva a cabo a pesar de la guerra» ${ }^{63}$.

Más complicado es establecer si la propaganda republicana o franquista tuvo mayor éxito (entendido el mismo como mayor difusión de sus ideas en vista a lograr presión efectiva del ciudadano extranjero para lograr de sus gobiernos una implicación real y directa en la Guerra Civil española) en su época y a posteriori (pervivencia de una memoria y tópicos que se han ido transmitiendo de generación en generación hasta los tiempos actuales). Si tomamos como vara de medición los sondeos de Opinión Pública elaborados a nivel internacional, entre 1936 y 1939, apreciamos un mayor soporte a la República ${ }^{64}$. Sin embargo, este respaldo popular no impidió que las principales democracias europeas cortasen las posibles ayudas económicas y militares al Gobierno republicano (recuérdese las cortapisas del Comité de No-Intervención). De igual manera, la propaganda franquista no logró acelerar el reconocimiento diplomático hasta que la victoria militar en la guerra era una realidad irrefutable. Desde un punto de vista muy pragmático, toda la parafernalia propagandística rebelde y republicana tuvo escasa rentabilidad política, pues el destino de la contienda bélica se insertó en un complicado tablero de geoestrategia mundial, donde el apoyo nazifascista a Franco y los constreñimientos externos que impactaron sobre la República, fueron beneficios / obstáculos (según el caso), que no hubiese podido "salvar la mejor, la más excelsa, la más motivada y la más eficiente estrategia exterior ${ }^{65}$. Desde otro plano, el estudio de esta propaganda -en cualquiera de sus facetas- es imprescindible para conocer y comprender acertadamente las culturas de guerra en el siglo XX. Como apuntaba el historiador Hugo García, y retrotrayéndonos de nuevo a la pregunta sobre la perduración de la propaganda de la Guerra Civil en el sentir de las futuras generaciones, «desmentida por la Segunda Guerra Mundial, ideológica y

\footnotetext{
${ }^{63}$ AMAE, R. 4000/2. "Nota sobre los problemas de propaganda a favor de la España Nacional en los Estados Unidos de América», 25 de abril de 1938.

${ }^{64}$ El Instituto británico de Opinión Pública ofrecía, con mínimas variaciones, preferencia de la población por la República española. En 1939 este soporte se situó en un 90 por ciento. Algo muy similar ocurría en EE.UU., en especial en Nueva York, donde los principales medios periodísticos se alinearon a lo largo de toda la guerra con las tesis británicas. Vid., BUCHANAN, Tom: Britain and the spanish Civil War. Cambridge: Cambridge University Press, 1997, p. 23; y AGA, Exteriores, caja 8578. «Escritos núm. 41 y 43 del Ministro Consejero, Enrique Carlos de la Casa, a la Embajada de España en Washington», 26 de agosto de 1937 y 7 de septiembre de 1937.

${ }^{65}$ VIÑAS, Ángel (dir.): Al servicio de la República...op. cit., p. 423.
} 
estéticamente pobre, la propaganda nacional ha envejecido mucho peor que la republicana» ${ }^{66}$.

\section{Referencias bibliográficas}

AMAR, Hanania A. (2011): Arthur Koestler. La rage antitotalitaire, París, L'Harnattan.

ASHOLT, Wolfgang (2008): España en el corazón: der Spanische Bürgerkrieg. Medien und Kulturelles Gedächtniss, Bielefeld, Aisthesis.

BALDAUF, Heinrich (1937): Christen im spanische Sturm. Tatsachenberichte zur Verfolgung der Kirche in Spanien, Saarbrücken, Saarbrücken Druckerei und Verlag AG.

BANNASCH, Bettina (2005): Erimern und erzählen: der Spanische Bürgerkrieg in der deutschen und spanischen Literatur und in den Bildmedien, Tübingen, Gunter Narr Verlag, 2005.

BENIT, André (1996): La guerre civile espagnole dans la littérature belge: Paul Nothlomb: histoire, romans et mythe, Madrid, Universidad Complutense de Madrid.

BUITENHUIS, Peter (1987): The Great war of words. Literature as Propaganda, 19141918 and after, London, Bastford Ltd.

CAILLAT, Michel (2007): "L' Entente internationale anticommuniste, 1924-1939. Lorsque Genève était la capitale mondiale de l'anticommunisme", Solidarités, Cahiers émancipations, n. 110, pp. 1-4.

CAL, Rosa (2012): "Onaindia: propagandista contra el franquismo", Miguel Hernández Communication Journal, n.ำ 4, 2012, pp. 11-36.

CASAS, José Luis (2013): Por lealtad a la República. Historia del canónigo Gallegos Rocafull, Barcelona, Editorial Base.

COLE, Sarah (2012): At the Violent Hour: Modernismo and Violence in England and Ireland, New York, Oxford University Press.

CULL, Nicholas John (1995): Selling war. The British Propaganda Campaign Against American "Neutrality" in World War II, Oxford, Oxford University Press.

\footnotetext{
${ }^{66}$ GARCÍA, Hugo: Mentiras necesarias..., op. cit., p. 239.
} 
DE LA HERA MARTÍNEZ, Jesús (2002): La política cultural de Alemania en España en el periodo de entreguerras, Madrid, CSIC.

DÍAZ-PLAJA, Fernando (1980): La caricatura española en la Guerra Civil, dentro de la revista Tiempo de Historia, n.o 73.

EYKMAN, Christoph (1992): "The Spanish Civil War in German Publications during the Nazi Years", en COSTA, Luis et alli: German and International Perspectives on the Spanish Civil War: the Aesthetics of Partisanship, Columbia, Candem House, pp. 166-178.

GALLEGO, José Andrés y PAZOS, Antón M. (2009): Archivo Gomá. Documentos de la guerra civil, Vol. IX.

GARCÍA FERNÁNDEZ, Hugo (2009): "Relatos para una guerra. Terror, testimonio y literatura en la España nacional", Ayer, n.o 76, 2009, pp. 143-176.

GOEBBELS, Josef (1937): La verdad sobre España. Discurso pronunciado en Nuremberg en el Congreso Nacional del Partido en 1937.

GONZÁLEZ CALLEJA, Eduardo (2000): "Reflexiones sobre el concepto de Guerra Civil", Gladius $X X$.

GROGNARD, Christian (1987): "Une guerre religieuse et patriotique. Positions d' un hebdomaire de droite: la revue catholique des idées et des faits", Revue Belgue d'Histoire Contemporaine, núm. 3/4, pp. 691-724.

HENCH, John B. (2010): Books as weapons. Propaganda, publishing and the Battle for Global Markets in the Era of World War II, USA, Cornell University Press;

HIRIARTIA, J. de (1938): Le Cas des Catholiques Basques, París, Chez H. G. Peyre.

HOLMAN, Valerie (2008): Print for Victory. Book Publishing in England, 1939-1945, London, British Library.

KALLIS, Aristotle, A. (2005): Nazi Propaganda and the Second World War, Palgrave McMillan.

KEEN, Sam (1986): Faces of the enemy. Reflections of the Hostile Imagination, San Francisco, Harper and Row.

LUCKERT, Steve y BACHRACH, Susan (2011): State of Deception. The power of Nazi Propaganda. Washington, 2011.

LUTZ, Winckler (1979): La función social del lenguaje fascista, Barcelona, Ariel. 
MAYOR FERRÁNDIZ, Teresa M.a (2011): "John Heartfield, un artista antinazi", en Revista de Claseshitoria. Publicación digital de Historia y Ciencias Sociales, n.으 190.

MONTEATH, Peter (1994): Writing the Good Fight: Political Commitment in the International Literature of the Spanish Civil War, Greenwood Press.

MONTEATH, Peter y ELKE, Nicolai (1986): Zur Spanienkriegsliteratur. Die Literatur des Dritten Reiches Zum Spanischen Bürgerkrieg, Frankfurt am Main, Verlag Peter Lang.

MONTERO, Feliciano, MORENO CANTANO, Antonio César y TEZANOS, Marisa: Otra Iglesia. Clero disidente durante la II República y la Guerra Civil, Gijón, Trea (en prensa).

MOOR, Vincent de (1938): L'horreur rouge en terres d'Espagne, Bruxelles, B.U.P

PETER, Antonio (1992): Das Spanienbid in den Massenmedien des Dritten Reichen, 1933-1945, Frankfurt am Main, Peter Lang.

ROULIN, Stephanie (2010): Un credo anticommuniste. La Comisión Pro Deo de I'Entente internationale anticommuniste ou la dimension religieuse d'un combat politique (1924-1945), Lausanne, Éditions Antipodes, 2010.

SCHÜLER-SPRINGORUM, Stefanie (2007): "Las representaciones de la violencia en la Guerra Civil española: el ejemplo alemán", Alcores, n. 4, pp. 39-54.

SCHULZE SCHNEIDER, Ingrid (2001): "Josef Goebbels, 'historiador' de la Guerra Civil española", Historia y Comunicación Social, n.o 6.

SEVILLANO CALERO, Francisco (2007): Los rojos. La representación del enemigo en la Guerra Civil, Madrid, Alianza Editorial.

SOUTHWORTH, Herbert R. (1977): Guernica! Guernica! A study of Journalism, Diplomacy, Propaganda and History, Berkeley, University of California Press. ${ }^{1}$ HOOGS, Georges (1937): Le drame de l'Espagne. Croisade morale ou Guerre sociale?, París, La Jeune-République.

TOLL, Gil (2013): Heraldo de Madrid. Tinta catalana para la II República Española, Sevilla, Editorial Renacimiento.

VINCENTE, Mary (2007): "La Guerra Civil española como Guerra de Religión", Alcores. Revista de Historia Contemporánea, núm. 4.

ZEMAN, Z.A.B. (1973): Nazi Propaganda, Londres, Oxford University Press. 